\title{
A First Cytogenetic Study of Down Syndrome in Albania
}

\author{
Anila Babameto - Laku', Dorina Roko ${ }^{2}$ \\ ${ }^{1}$ UHC “Mother Teresa”, University of Medicine, Service of Medical Genetics, Tirana, Albania \\ ${ }^{2}$ UHC "Mother Teresa", Service of Medical Genetics, Tirana, Albania
}

\begin{abstract}
Down syndrome (DS) also known as trisomy 21 is a genetic complex disorder and the most common and best known autosomal chromosome abnormality in humans. Even though the majority of cases of DS can be identified based on clinical findings, cytogenetic analysis is essential to confirm the diagnosis and to provide information for genetic counseling. The present study is the first national consecutive series of Down Syndrome in Albanian population during the period 1984-2015. This study allowed the frequency of three basic cytogenetical types and the frequency of occurrence of the rarer karyotypes of Down syndrome to be estimated. Also the maternal age effect on the frequency of births of children with Down syndrome was evaluated. The frequency of occurrence of the different karyotypes was analyzed. The free trisomy 21 was the most common karyotype (nearly $91 \%$ of all cases). The ratio of mosaic trisomy 21 was $2.1 \%$. The ratio of Robertsonian and reciprocal translocations were $5,7 \%$ and $0.2 \%$, respectively. The chromosomal abnormalities (CAs) in addition to trisomy 21 were present in 0,8\% of all cases. Conclusions: Knowledge of the cytogenetic types are essential and carried out greatly helped in the management of these children and for counseling the affected families.
\end{abstract}

Keywords: Down syndrome, free trisomy 21, Robertsonian translocation, karyotype, genetic counseling.

\section{Introduction}

Down syndrome (DS) also known as trisomy 21 is a genetic complex disorder and the most common and best known autosomal chromosome abnormality in humans. It is characterized by well-defined and distinctive phenotypic features that is caused by the presence of all or part of a third copy of chromosome 21 (9).

Different karyotypes are associated with varying phenotypic expression of DS. The type of karyotypes in the children with DS plays an important role in genetic diagnosis and family counseling. In $93-96 \%$ of the individuals the chromosome consistency is an extra chromosome 21, whereas $2-3 \%$ occurs due to mosaicism. In the remaining 2$5 \%$ the DS occurs due to Robertsonian translocation or rarely reciprocal translocation (6). The free trisomy 21 is the most common karyotype. It occurs sporadically de novo as a result of nondisjunction of homologous chromosomes 21 during gametogenesis to parents.

Mosaicism often arises as a post zygotic error (4). Peoples with mosaic Down syndrome have two distinct cell lines with different karyotype. In some cells there are a total of 46 chromosomes having normal karyotype, while other cell lines have karyotype with Trisomy in chromosome 21 (5).

In children with Down syndrome due to translocation, extra chromosome 21 is joined or translocated in any other acrocentric or non-acrocentric chromosome (10). The translocation present in Down syndrome patients can be created spontaneously de novo during gametogenesis in one of the parents or it can be inherited from parents carrier of Robertsonian translocation or of reciprocal translocations. The frequency to have one child with Down's syndrome due to translocation trisomy 21 is not influenced by the age of the mother. There is a significant increased risk of giving birth to a child with Trisomy 21 when one parent is a
Robertsonian translocation carrier or of reciprocal translocations as they may produce balanced and unbalanced gametes during gametogenesis $(1,2)$.

Several children involving autosome and/or sex chromosome aneuploidy, such as double autosomal trisomy and autosomal trisomy with sex chromosome monosomy or trisomy though rare in live borns have also been reported (11).

The most common risk factor for Down syndrome is maternal age. As a woman gets older, her risk to have a pregnancy with a chromosome abnormality increases (3).

Even though the majority of cases of DS can be identified based on clinical findings, cytogenetic analysis is essential to confirm the diagnosis and to provide information for genetic counselling to such families about the possibility of having another child with the same disability.

In this report we present the frequencies and distributions of the postnatal prevalence of chromosomal abnormalities (CAs) in children and newborns with DS physical features in Albania for the time period 1984-2015.

\section{Material and Methods}

The cases in this study are retrospectively evaluated children and newborns for suspicion of DS, postnatally. They were subjected to detailed morphological and cytogenetic analysis. Firstly, children have been seen and diagnosed clinically by the Service of Medical Genetics in the University Hospital Centre "Mother Teresa", Faculty of Medicine, Tirana, Albania, and then the cytogenetic analysis was performed in the Cytogenetic Laboratory of this service. Since that lab is the only laboratory for cytogenetics in Albania, all the cases suspected of having Down syndrome were diagnosed there. 


\section{International Journal of Science and Research (IJSR) \\ ISSN (Online): 2319-7064 \\ Index Copernicus Value (2013): 6.14 | Impact Factor (2014): 5.611}

Standard techniques for the cultivation of lymphocytes from peripheral blood of children were used and the preparations were treated to obtain G-banding. The analyses were performed on 50 cells. Karyotypes were documented according to standard procedures of International System for Human Cytogenetic Nomenclature (ISCN, 2009).

\section{Results}

A total of 685 children were registered during a 31 years period, 1984-2015. Succesful cytogenetic analyses were available for 479 children. Maternal age varied from 16 to 49 years with mean age of 30,4 years old.

Karyotype results were divided into four categories: free trisomy 21 , mosaic trisomy 21 , translocations and CAs in addition to trisomy 21 , are shown in Table 1 .

Table 1: Frequencies and distributions of the karyotypes in children for suspicion of Down syndrome

\begin{tabular}{|c|c|c|c|c|c|}
\hline No. & \multicolumn{2}{|c|}{$\begin{array}{c}\text { Cytogenetic types of Down } \\
\text { Syndrome }\end{array}$} & Karyotypes & No. of cases & Frequency in all cases $(\%)$ \\
\hline 1. & \multicolumn{2}{|l|}{ Free trisomy 21} & $47, \mathrm{XX},+21$ or $47, \mathrm{XY},+21$ & 436 & 91 \\
\hline 2. & \multicolumn{2}{|c|}{ Mosaic trisomy 21} & $46, \mathrm{XX} / 47, \mathrm{XX},+21$ or $46, \mathrm{XY} / 47, \mathrm{XY},+21$ & 10 & 2,1 \\
\hline \multirow[t]{4}{*}{3.} & Translocation & $13 ; 21$ & $46, \mathrm{XY}, \mathrm{t}(13 ; 21)(\mathrm{q} 10 ; \mathrm{q} 10)$ & 1 & 0,2 \\
\hline & Translocation & $14 ; 21$ & $\begin{array}{l}46, \mathrm{XX}, \mathrm{t}(14 ; 21)(\mathrm{q} 10 ; \mathrm{q} 10) \text { or } \\
46, \mathrm{XY}, \mathrm{t}(14 ; 21)(\mathrm{q} 10 ; \mathrm{q} 10)\end{array}$ & 16 & 3,3 \\
\hline & Translocation & $21 ; 21$ & $\begin{array}{l}46, \mathrm{XY}, \mathrm{t}(21 ; 21)(\mathrm{q} 10 ; \mathrm{q} 10) \text { or } \\
46, \mathrm{XX}, \mathrm{t}(21 ; 21)(\mathrm{q} 10 ; \mathrm{q} 10) \\
\end{array}$ & 11 & 2,2 \\
\hline & Reciprocal & & $46, \mathrm{XY}, \mathrm{t}(10 ; 21),+21$ & 1 & 0,2 \\
\hline \multirow[t]{4}{*}{4.} & \multirow{4}{*}{\multicolumn{2}{|c|}{$\begin{array}{l}\text { Chromosomal aberrations in } \\
\text { addition to trisomy } 21\end{array}$}} & $47, \mathrm{XX}, \mathrm{t}(4 ; 21)(\mathrm{q} 27 ; \mathrm{q} 22),+21$ & 1 & 0,2 \\
\hline & & & $47, \mathrm{XY}, \mathrm{t}(4 ; 5)(\mathrm{q} 31.2 ; \mathrm{q} 33),+21$ & 1 & 0,2 \\
\hline & & & $48, \mathrm{XXX},+21$ & 1 & 0,2 \\
\hline & & & $48, X Y Y,+21$ & 1 & 0,2 \\
\hline
\end{tabular}

Free trisomy 21 was the most common karyotype $(91 \%$ or 436 cases) among CAs with cytogenetic formula 47,XX, +21 or 47, XY, +21. Mosaic Down syndrome for free trisomy 21 with karyotype $46, \mathrm{XX} / 47, \mathrm{XX}+21$ or $46, \mathrm{XY} / 47, \mathrm{XY}+21$ was found in 10 children $(2,1 \%)$. Parental somatic mosaicism by chromosome analysis was confirmed only in a mother of two affected children with free trisomy 21 .

In 28 children $(5.7 \%)$ have been detected trisomy 21 with Robertsonian translocation created by merging of chromosome 21 with another acrocentric chromosome. Most of investigated children had Robertsonian translocation formed between chromosomes $(14 ; 21)$. This translocation type is found in $16(3.3 \%)$ children. From their parents we found this translocation in three mothers, which were the carrier parent of that translocation with karyotype $45, \mathrm{XX}$, $\mathrm{t}(14 ; 21)(\mathrm{q} 10 ; \mathrm{q} 10)$.
$11(2,2 \%)$ other children had Robertsonian translocation between chromosomes 21 and 21. Robertsonian translocation between chromosome 13 and 21 was found only in one child. Reciprocal translocation between chromosome 21 and 10 is found in only one child too.

In 2 cases $(0,4 \%)$, regular trisomy 21 was associated with structural CAs such as $\mathrm{t}(4 ; 21)$ and $\mathrm{t}(4 ; 5)$. In the 2 other cases $(0,4 \%)$, regular trisomy 21 was associated with numerical CAs, followed by $47, \mathrm{XX},+21$ or $47, \mathrm{XY},+21$ aneuploidy. (Table 1).

Two Robertsonian rearrangements and two types of balanced translocations with free trisomy 21 which were confirmed by cytogenetic analysis are showed below (Fig 1a, b, c, d).

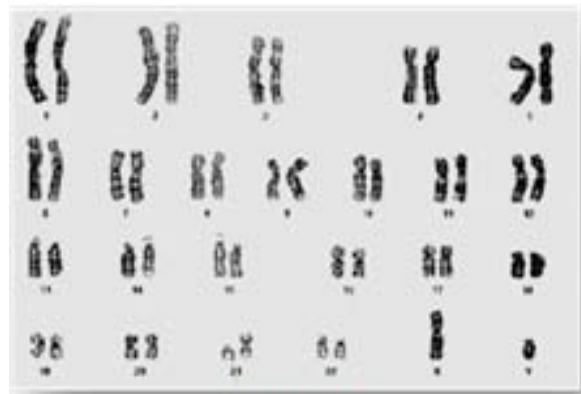

Figure 1a

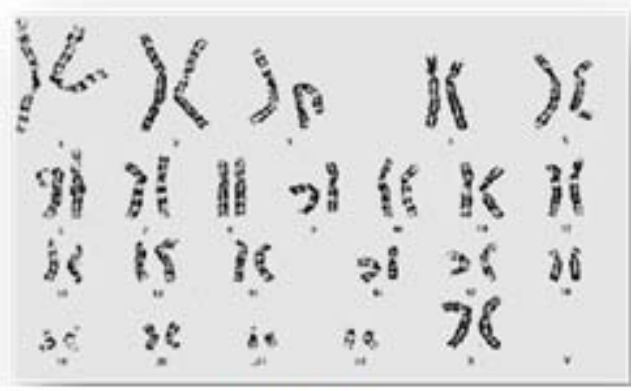

Figure 1b 
International Journal of Science and Research (IJSR)

ISSN (Online): 2319-7064

Index Copernicus Value (2013): 6.14 | Impact Factor (2014): 5.611

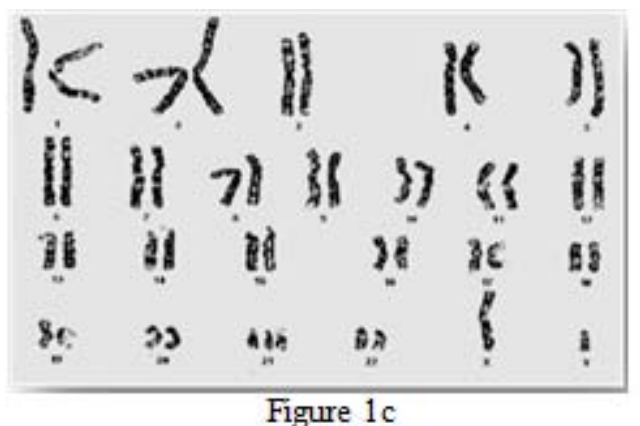

Figure 1c

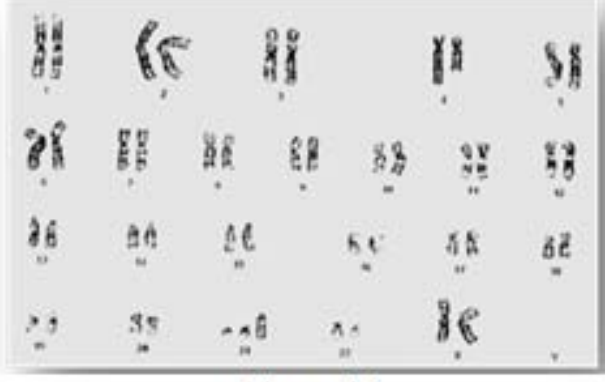

Figure 1d
G-banded karyotype

Fig. 1a 46,XY, t(21;21) (q10;q10)

Fig. 1b 46,XX, t(14;21)(q10;q10)

Fig. 1c 47,XY, t(4;5)(q31.2;q33),+21

Fig. 1d 47,XX, t(4;21)(q27;q22), +21
Our focus in this study was also to investigate birth frequency of children with Down syndrome to mothers of different age. In these cases maternal age at pregnancy was between 16 - 49 years old. To know the role of maternal age in Down's syndrome children with free trisomy 21 six different age groups were made (Graphic 1.)

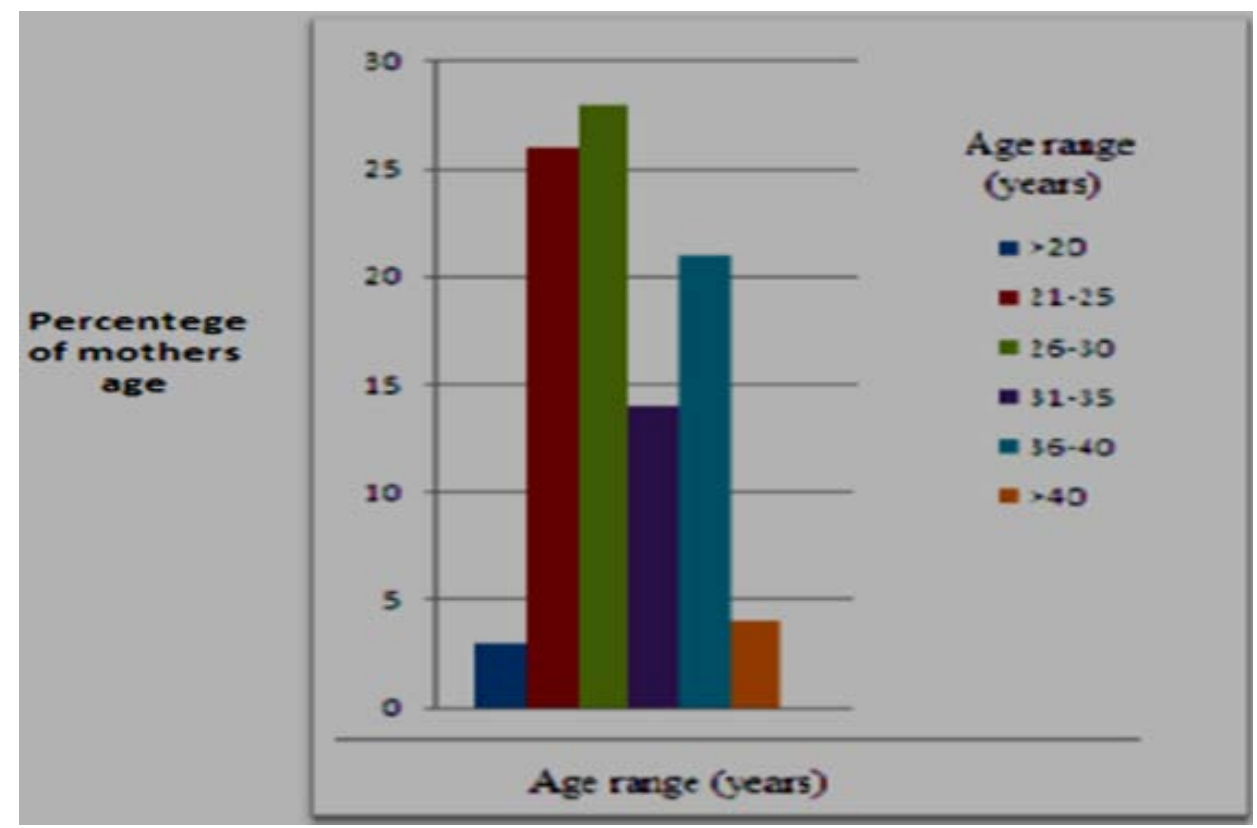

Graphic 1: Distribution of maternal age in Down's syndrome cases with free trisomy 21

\section{Discussion}

The present study is the first national consecutive series of Down Syndrome in Albanian population during the period 1984-2015 and is aimed to document the types of cytogenetic abnormality in DS children and their relation to maternal age.

The cytogenetical study conducted on 479 Down syndrome children revealed that free trisomy 21 is significantly more frequent $(91 \%)$ than the other types of trisomy 21 , whereas $2,1 \%$ occurs due to mosaicism. For the parents of a child affected by free trisomy 21 , the recurrence risk is only slightly modified. Confirmation of somatic parental mosaicism, was by identification of maternal transmission of the extra chromosome to the progeny, in a case of the presence of more than one affected child.

Since the free trisomy 21 is the most common genetic cause of birth of children with DS it is of great importance to undertake preventive measures in order to reduce the disorder incidence among human population.
Our results are roughly similar to the results of other authors. In their studies also indicated high occurrence of free trisomy 21 (92-95\%) in children that have Down syndrome $(7,12,13)$. The small differences among these studies may be due to the size of the samples. Studies of many authors have shown that one of the factors which increase the incidence of births with free trisomy 21 is advanced maternal ages $(7,8,15)$. Other factors such as physical, biological and chemical mutagens, have also been found to cause non disjunction.

Very often Down's syndrome babies are born to mothers who are over than 35 years of age. Our data confirmed that in maternal age up to 20 years the incidence's birth of children with Down syndrome is lower due to the smaller number of women births compared to higher risk among older women, therefore Down's syndrome children born to mothers of advanced age 21-30 years gradually increasing (Graphic 1). This increase is in correlation with the increasement of total number of births in the general population as well, which occurs most frequently at those ages in parallel with the birth of children with Down 


\section{International Journal of Science and Research (IJSR) \\ ISSN (Online): 2319-7064 \\ Index Copernicus Value (2013): 6.14 | Impact Factor (2014): 5.611}

syndrome. Although the number of children born with Down syndrome in this period at first sight seems to be higher, however if the number is analyzed for total ratio of births at this period it shows no higher incidence than in older women. There is a small decrease in the frequency of live births with Down syndrome among women aged 30-35 years. This decrease can be related to the reduction in the total number of births in general population, where the birthrate of women over the age of 35 gradually decreases until the end of their reproductive periods. In the general population, there is a parallelism on increasing the number of births of normal and of Down syndrome children by age of 35 . Women aged 35 to 40 have a permanent increase of the birth of children with Down syndrome which is not in proportion with the increase of births in the general population, since at this age the number of births in the general population decreases. The increase of Down syndrome births to mothers in this age showing a direct correlation between Down syndrome and maternal age.

Chromosome 21 most frequently creates translocations with acrocentric chromosomes than to other non-acrocentric autosomal. In the present study, all translocations were found in 29 cases, 28 of them were with Robertsonian translocation.

The most frequent type of translocation were the Robertsonian translocation 14q; 21q (16 cases).

Cytogenetical analysis of the parents of children affected with this Robertsonian translocation revealed that in three children translocation was inherited by one of carrier parent of that translocation, from the mothers respectively with karyotype: 45,XX, t(14;21)(q10;q10).

Karyotype of the children were $46, \mathrm{XX}, \mathrm{t}(14 ; 21)(\mathrm{q} 10 ; \mathrm{q} 10)$ as a result of disjunction $2: 1$ and of adjacent-1 segregation during meiosis in her mother. Since an affected child with Robertsonian translocation 14q; 21q, have inherited translocation from their mother side, the recurrence risk is significantly much higher (10-15\%). By applying the prenatal cytogenetic diagnosis of embryos of each of these couple pregnancies can be prevented the spread of Down syndrome within a generation.

In the 13 other children was found de novo translocation. In the families who have children with translocation trisomy 21 arisen de novo, the parents have normal karyotype and the risk of giving birth to a child with translocation trisomy 21 is small $(1-2 \%)$. This risk is not influenced by the age of the mother.

We found also de novo translocations in children with translocation between $13 ; 21$ and $21 ; 21$ too.

Reciprocal translocation between chromosome 21 and 10 was found only in one child $(0.2 \%)$ with Down syndrome.

One child with Down syndrome had inherited the translocation 4;21 from her mother. She was a carrier of reciprocal translocation $4 ; 21$ and of trisomy 21 , with cytogenetic formula: 47,XX, $\mathrm{t}(4 ; 21)(\mathrm{q} 27 ; \mathrm{q} 22),+21$. The child's mother was a silent carrier of a balanced translocation with karyotype: 46,XX,t(4;21)(q27;q22). The child having this chromosomal aneuploidy was as a result of disjunction 3:1 of derived chromosomes 4 and 21 and their normal homologues during gametogenesis in her mother (Interchange trisomy 21). In one another child we found a translocation $\mathrm{t}(4 ; 5)$ with cytogenetic formula 47,XY, $\mathrm{t}(4 ; 5)(\mathrm{q} 31.2 ; \mathrm{q} 33),+21$. This translocation was inherited from her mother that was a carrier of this translocation with cytogenetic formula 46, XX,t $(4 ; 5)(\mathrm{q} 31.2 ; \mathrm{q} 33)$.

Two children, involving sex chromosome aneuploidy with free trisomy 21 , such as $48, \mathrm{XXX},+21$ and $48, \mathrm{XYY},+21$ have been reported. These cytogenetic formula also have been reported in another studies $(10,11)$. Double aneuploidy leading to trisomy of 2 different chromosomes arise because of 2 meiotic non-disjunctional events (14). Our data reemphasizes the need for cytogenetic analysis in young children with Down syndrome even if the phenotype is typical, so that any associated abnormality may be detected. The developmental, cognitive and behavioral profile of children with sex chromosome aneuploidy differs from trisomy 21 and warrants regular follow-up and interventions to optimize the developmental potential of the child.

\section{Conclusion}

This results support that trisomy 21 has a universal genetic etiology across different human populations. Free trisomy 21 karyotype is more frequent in DS cases in Albanian children with Down syndrome than translocation and mosaic karyotypes. The chromosome rearrangements need to be followed up by karyotiping the parents, because they are essential for counseling the affected families.

The cytogenetic analysis is needed in young children with Down syndrome even if the phenotype is typical, so that any associated abnormality may be detected. The type of karyotypes in the children with DS plays an important role in genetic diagnosis, management of these children and family counselling.

\section{References}

[1] Balkan M, Akbas H, Isi H, Oral D, Turkyilmaz A, et al. (2010) Cytogenetic analysis of 4216 patients referred for suspected chromosomal abnormalities in Southeast Turkey. Genetics and Molecular Research 9: 10941103.

[2] Duarte AC, Cunha E, Roth JM, Ferreira FLS, Garcias GL, et al. (2004) Cytogenetics of genetic counseling patients in Pelotas, Rio Grande do Sul, Brazil. Genet Mol Res3: 303-308.

[3] Egan JF, (2004) Down syndrome births in the United States from 1989 to 2001. Am J Obstet Gynecol, 191(3): 1044-8.

[4] Kovaleva NV, Mutton DE (2005) Epidemiology and double aneuploidies involving chromosome 21 and the sex chromosomes. Am J Med Genet, 134A: 24-32.

[5] Mutton D, Alberman E, Hook EB (1996) Cytogenetic and epidemiological findings in Down Syndrome, England and Wales 1989 to 1993 . J Med Genet 33: 387 394.

[6] Miller OJ, Therman E (2001) Human Chromosomes. Springer-Verlag (4th edn), New York, 245.

\section{Volume 5 Issue 2, February 2016}




\section{International Journal of Science and Research (IJSR) \\ ISSN (Online): 2319-7064}

Index Copernicus Value (2013): 6.14 | Impact Factor (2014): 5.611

[7] Owens JR, Harris F, Walker S, McAllister E, West L (1983) The incidence of Down's syndrome over a 19year period with special reference to maternal age. J Med Genet 20: 90-93.

[8] Pui CH, Raimondi SC, Borowitz MJ, Land VJ, Behm FG, et al. (1993) Immunophenotypes and karyotypes of leukemic cells in children with Down syndrome and acute lymphoblastic leukemia. J ClinOncol 11: 1361.

[9] Patterson, D (Jul 2009)."Molecular genetic analysis of Down syndrome". Human Genetics 126 (1): 195-214.

[10] Rivera H, Gutiérrez-Angulo $M$, Gómez-Sánchez $H$, Macias-Gomez N, Barros-Núñez P, et al. (2002) True vs. false $\operatorname{inv}(\mathrm{Y})(\mathrm{p} 11 ; \mathrm{q} 11.2)$ : a familial instance concurrent with trisomy 21. Ann Genet45: 63-65.

[11]Reddy KS (1998) Double trisomy in spontaneous abortions. Hum Genet 101: 339-345.

[12] Richards BW (1974) Investigation of 142 mosaic Mongols and mosaic parents of Mongols; cytogenetic analysis and maternal age at birth. J MentDefic Res 18: 199-208.

[13] Shott SR, Joseph A, Heithaus D (2001) Hearing loss in children with Down syndrome. International Journal of Pediatric Otorhinolaryngology 61: 199-205.

[14] Suhair S. Eid MSc, Montaha M. Shawabkeh (2009) Double Trisomy 48,XXY,+21 in a Child With Phenotypic Features of Down Syndrome. Oxford University Press, 215-218.

[15]Zwaan MC,Reinhardt D, Hitzler J, Vyas P (2008) Acute leukemias in children with Down syndrome. PediatrClin North Am. 55: 53-70.

\section{Author Profile}

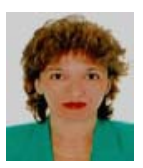

Anila Babameto-Laku (Corresponding author) is Professor of Medical Genetics, in the University and postuniversity level in the Faculty of Medicine of Medical University of Tirana. Responsabile of the cytogenetic laboratory and genetic counseling clinic in the Service of Medical Genetics, University Hospital Center "Mother Teresa", Tirana, Albania. Graduated in Faculty of Medicine in Tirana in 1985, is specialized in general pathology in 1986-1989 and medical genetics in 1989-1992. Author of 109 scientific publications, 62 of them in international magazines and proceeding books.

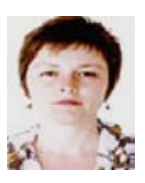

Dorina Roko received the B.Sc and M.Sc for biology in the Faculty of Natural Science, University of Tirana, Albania in 2005 and 2009 respectively. Graduated with $\mathrm{PhD}$ degree in 2014 in biology field. Currently work as a cytogenetist at Genetic Service in Cytogenetic laboratory in University Hospital Center "Mother Teresa", Tirana, Albania. 